04

\title{
Голографические оптические компоненты на основе фоторефрактивных кристаллов и стекол: сравнительный анализ и перспективы развития
}

\author{
(C) Н.В. Никоноров, В.М. Петров
}

\author{
Университет ИТМО, \\ 197101 Санкт-Петербург, Россия \\ e-mail: vikpetroff@mail.ru
}

Поступила в редакцию 30.11.2020 г.

В окончательной редакции 30.11.2020 г.

Принята к публикации 22.12.2020 г.

\begin{abstract}
Представлен обзор оригинальных результатов исследования оптических и голографических свойств двух видов фоточувствительных материалов, используемых в современной оптической голографии: легированных кристаллов ниобата лития и фото-терморефрактивных стекол. Приведен сравнительный анализ основных голографических характеристик этих материалов. Показаны преимущества и недостатки фототерморефрактивных стекол и кристаллов ниобата лития, а также наиболее значимые примеры их практических применений в фотонике.
\end{abstract}

Ключевые слова: ниобат лития, фото-терморефрактивное стекло, объемные брэгговские решетки, голографические оптические элементы.

DOI: $10.21883 /$ OS.2021.04.50764.290-20

\section{Введение}

В настоящее время особое место среди большого разнообразия органических и неорганических фоточувствительных материалов для голографической записи информации занимают неорганические фоторефрактивные стекла и кристаллы. В отличие от тонких голограмм толщиной $\sim 10 \mu \mathrm{m}$, которые характеризуются параметром Кляйна $Q \sim 10$ [1], эти среды позволяют записывать сверхглубокие голограммы толщиной в десятки миллиметров $(Q>1000)$ :

$$
Q=\frac{T \lambda_{R}}{n \Lambda^{2}}
$$

Здесь $\lambda_{R}$ - длина волны падающего (считывающего) света, $\lambda$ - пространственный период решетки, $T$ толщина решетки, $n-$ средний показатель преломления материала, в котором записана решетка (рис. 1).

Кроме того, по сравнению с фоточувствительными полимерами, галоидосеребряными эмульсиями и бихромированной желатиной кристаллы и стекла имеют высокие эксплуатационные характеристики (высокая механическая, термическая и оптическая прочность, твердость, абразивоустойчивость, химическая устойчивость и т.д.). К фоторефрактивным кристаллам и стеклам применима технология механической обработки поверхности - обычное и глубокое шлифование и полирование, и это позволяет делать из них объемные оптические элементы (линзы, призмы, пластины, стержни и т.д.), что практически невозможно реализовать на полимерах, эмульсиях, желатине. Эти характеристики делают кристаллы и стекла крайне востребованными для создания голографических оптических элементов и устройств нового поколения. В свою очередь, у фоторефрактивных кристаллов и стекол есть свои достоинства и недостатки, которые разграничивают и определяют их области применения. Так, например, к достоинствам фоторефрактивных кристаллов можно отнести их высокие и разнообразные активные характеристики (нелинейнооптические, электрооптические, фоторефрактивные) по сравнению со стеклами. В то же время стекла допускают применение к ним более разносторонних технологий, которые невозможно реализовать для кристаллов, но которые крайне востребованы для голографических задач. К ним прежде всего можно отнести вытяжку оптического волокна, напыление, ионный обмен, полинг, прессование, молирование и т.д.

Пожалуй, одной из самых успешных и востребованных областей применения фоторефрактивных кристаллов и стекол является их использование в качестве эффективной среды для записи толстых (объемных) голограмм, отвечающих условиям дифракции Брэгга [2]. Здесь следует выделить два наиболее характерных примера широкого практического использования таких голограмм (или решеток): это оптические фильтры и динамические (адаптивные) светоделители.

В качестве оптических фильтров (пространственных, спектральных) используются так называемые „статические“ или постоянные отражательные решетки Брэгга, записанные в материале, который способен хранить голограмму практически неограниченное время. Голографические фильтры находят самое широкое применение в волоконно-оптических линиях связи для выделения требуемого частотного канала, а также в твердотельных 
и полупроводниковых лазерах для управления параметрами излучения. Так, например, в последние годы особое внимание привлекают к себе спектрально-селективные голографические элементы в связи с бурным развитием систем квантовых коммуникаций, в том числе с использованием боковых частот [3].

Отдельно следует выделить отражательные решетки, возникающие в активном материале (например, в неодимовом стекле) мощных импульсных лазеров при интерференции волн, распространяющихся внутри резонатора. В этом случае время формирования и релаксации решетки определяется характерными временами квантовых переходов вещества. Такие решетки оказывают заметное влияние на спектральные характеристики генерируемого излучения [4].

В настоящей работе приведен обзор оригинальных результатов, полученных в университете ИТМО, по исследованию и практическому применению двух видов фоточувствительных материалов: легированных кристаллов ниобата лития и фото-терморефрактивных стекол.

\section{Фото-терморефрактивные стекла}

Фото-терморефрактивные (ФТР) стекла - это новый класс фоточувствительных материалов, предназначенный для записи объемных фазовых голограмм. Прообразом (прототипом) ФТР стекол явилось полихромное (polychromic) стекло (ПХС), разработанное в американской компании Corning в 1977 г. [5-7]. В СССР эти стекла появились позже (в 80-е годы). Разработчиком этих стекол была лаборатория ГОИ им. С.И. Вавилова. Эти стекла имели тот же функционал, что и ПХС, и получили похожее название „мультихромные стекла“ (MXC) $[8,9]$. Главная особенность ПХС/МХC - селективное поглощение света в видимой области спектра. Широкую гамму окрасок эти стекла приобретают в результате следующих фотохимических и диффузионных процессов (фото-термоиндуцированной кристаллизации). Под действием УФ излучения и последующей
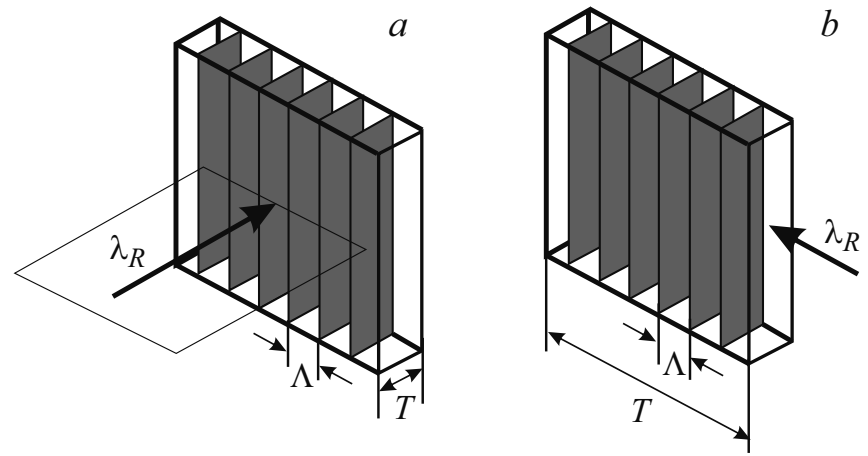

Рис. 1. Пропускающая $(a)$ и отражательная $(b)$ геометрии голографических решеток. $\lambda_{R}$ - длина волны падающего (считывающего) света, $\Lambda$ - пространственный период решетки, $T$ - толщина решетки (определяется в направлении считывающего света).

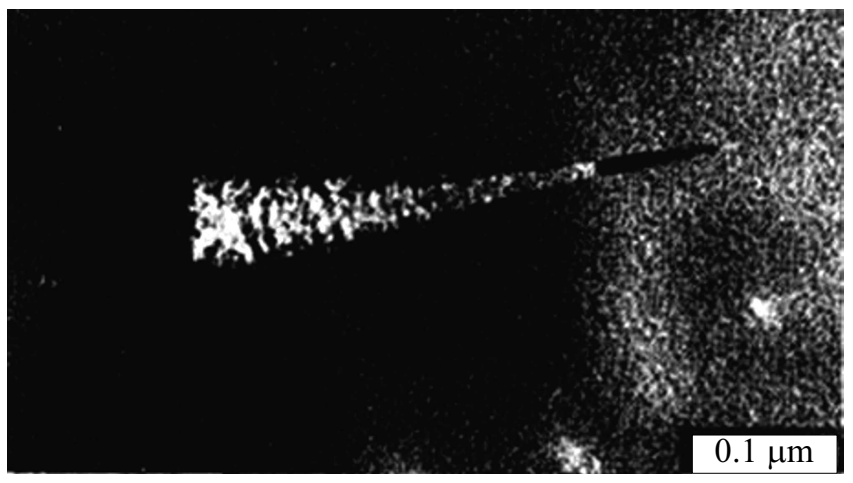

Рис. 2. Фотография микрокристалла фторида натрия вытянутой формы с покрытым металлическим серебром [7].

термической обработки образуются центры кристаллизации - металлические наночастицы серебра, и на этих центрах происходит рост нанокристаллов $\mathrm{NaF}-\mathrm{AgBr}$. При определенных условиях фото-термоиндуцированного роста эти нанокристаллы приобретают сложную анизотропную форму в виде вытянутых по одной оси конусообразных структур, похожих на плод моркови. Дополнительное многостадийное УФ облучение и термообработка приводят к фотолитическому осаждению серебра (декорированию) на вытянутых структурах. Металлическое серебро, осажденное на поверхность нанокристалла в виде оболочки, также приобретает анизотропную форму, что приводит к сдвигу полос поглощения в видимой области спектра. Таким образом, основным условием „Полихромного“/мультихромного окрашивания является анизотропная форма металлических наночастиц серебра (рис. 2).

Таким образом, в объеме стекла формируется разнообразная окраска, включая полную гамму цветов: синего, зеленого, желтого, оранжевого, красного и их производных, что позволяет записывать в стекле цветное изображение. Следует отметить, что несмотря на привлекательность записи цветного изображения в объеме стекла, ПХС и МХС пока до сих пор не нашли какоголибо широкого применения.

В конце 80-х начале 90-х годов в ГОИ им. С.И. Вавилова впервые предложили использовать процесс фототермоиндуцированной кристаллизации для записи объемных фазовых голограмм, а в качестве регистрирующей среды были выбраны ПХС/MХC [10-14]. В этом случае использовалась только одна стадия фототермоиндуцированной кристаллизации стекла — „облучение и термическая обработка“, при которой основное внимание уделялось не анизотропной форме микрокристаллов и сдвигу спектров поглощения, а различию в показателях преломления кристаллической и стеклообразной фаз. Это различие использовалось для записи объемных фазовых голограмм, в том числе брэгговских решеток. Более того, с анизотропной формой велась „борьба“, чтобы уменьшить размер нанокристаллов и 
ослабить рассеяние в записанных фазовых голограммах. Таким образом, в ГОИ было предложено новое название этого класса голографических материалов „фото-терморефрактивные стекла“ (ФТР стекла), т.е. стекла, в которых изменяется показатель преломления в результате облучения и последующей термической обработки. Это название закрепилось в голографическом сообществе, оно вытеснило названия ПХС и МХC и стало активно использоваться у нас в стране [10] и за рубежом $[15,16]$.

На протяжении последних 20 лет компания OptiGrate, университет Центральной Флориды (University of Central Florida, Orlando, USA) и Университет ИТМО (СанктПетербург, Россия) вели и в настоящее время ведут конкурентные исследования и разработки как самого ФТР стекла, так и элементов и устройств фотоники, сенсорики и лазерной техники. Повышенное внимание к ФТР стеклам прежде всего обусловлено их физикохимическими свойствами и возможностью изготавливать объемные дифракционные оптические элементы разного функционального назначения. Можно отметить следующие достоинства ФТР стекол и голограмм на их основе. Голограммы (в том числе, брэгговские решетки) могут быть записаны на большой глубине (0.1-10 mm). Записанные элементы имеют высокую дифракционную эффективность (до 99.9\%), а также угловую (менее $0.1 \mathrm{mrad}$ ) и спектральную (менее $0.01 \mathrm{~nm}$ ) селективность. Голограммы, записанные в ФТР стекле, обладают высокой химической устойчивостью, механической и термической прочностью, которые близки коммерческому оптическому стеклу К8 (зарубежный аналог ВК7). Кроме того, они выдерживают воздействие мощного непрерывного и импульсного лазерного излучения. Пороги оптического пробоя ФТР стекла близки к порогам пробоя коммерческого оптического стекла ВК7: 30-40 J/cm ${ }^{2}$ при импульсном облучении $(8 \mathrm{~ns}, \lambda=1064 \mathrm{~nm})$ и $100 \mathrm{~kW} / \mathrm{cm}^{2}$ при непрерывном облучении $(\lambda=1095 \mathrm{~nm})$ [17]. Также стоит отметить, что голограммы могут выдерживать многократный нагрев до высоких температур $\left(500^{\circ} \mathrm{C}\right)$ без потери своих свойств $[10,18]$.

Достоинством ФТР стекол как материала для записи голограмм также является его однородность (флуктуации показателя преломления в объеме порядка $\left.10^{-5}\right)$ и воспроизводимость характеристик как при синтезе исходного стекла подобно оптическому стеклу К8 (BК7), так и при фото-термоиндуцированной кристаллизации. ФТР стекла допускают применение традиционных методов механической обработки - шлифование и полирование, а также разнообразные технологии формования (например, прессование, молирование и создание асферических поверхностей). Также возможна вытяжка оптического волокна из ФТР стекла. Изготовление ФТР стекла можно осуществлять как в лабораторных (до 5-10 kg), так и в промышленных (до $300 \mathrm{~kg}$ ) условиях с использованием простой и нетоксичной технологии. При этом
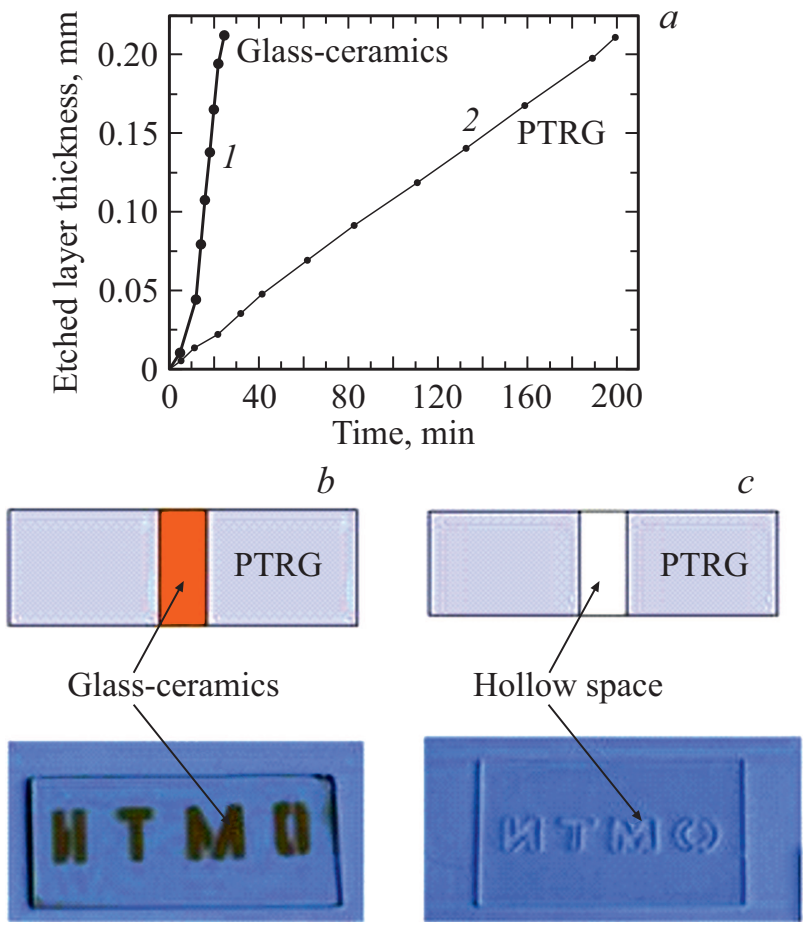

Рис. 3. Травление ФТР стекла (PTRG) в плавиковой кислоте и получение полых структур: $a-$ кинетика травления кристаллической фазы (1) и стекла $(2), b-$ исходный образец ФТР стекла с записанным изображением после УФ облучения и термообработки, $c$ - образец ФТР стекла после вытравливания кристаллической фазы.

химические реактивы, необходимые для синтеза стекла, являются коммерчески доступными и недорогими.

Следует также отметить некоторые необычные для регистрирующих сред свойства ФТР стекол. Так, ФТР стекла содержат щелочную компоненту (ионы натрия), и к таким стеклам применима ионообменная технология, например, возможно заменять ионы натрия в ФТР стекле на ионы серебра, калия, рубидия, цезия из внешнего источника - расплава соли. Эта технология позволяет повышать показатель преломления $\left(\Delta n=10^{-3}\right)$ на поверхности ФТР стекла и создавать ионообменные оптические $\mathrm{Ag}^{+}, \mathrm{K}^{+}, \mathrm{Rb}^{+}$и $\mathrm{Cs}^{+}$волноводы, а также упрочнять поверхность за счет сжимающих диффузионных напряжений [19]. Ионообменная технология позволяет повышать механическую, термическую и оптическую прочность ФТР стекла, а также его химическую устойчивость.

В работе [20] показано, что скорость травления закристаллизованной области материала в 10-15 раз выше скорости травления исходного стекла. Этот эффект позволяет создавать трехмерные мини- и микрофлюидные структуры в объеме ФТР стекла (рис. 3).

В работах [21-23] показана возможность легирования ФТР стекол редкоземельными ионами (неодимом, иттербием, эрбием), что открывает возможность записи брэгговских решеток непосредственно внутри активной 

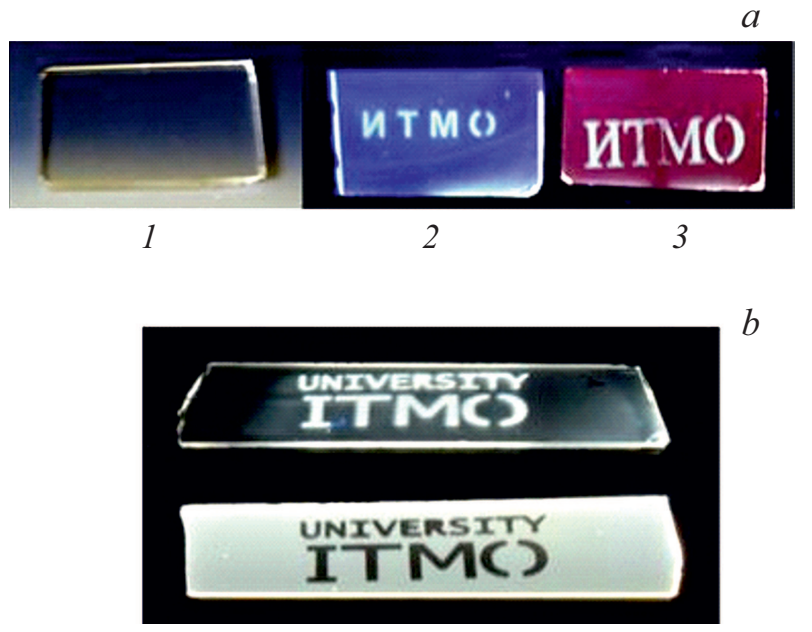

Рис. 4. Формирование люминесцентного изображения в объеме ФТР стекла: $a$ - исходный образец до УФ облучения (1), образцы при УФ облучении: классическое ФТР стекло (2), ФТР стекло, активированное европием (3); $b-$ люминесцентное изображение позитивной и негативной записи информации в ФТР стекле.

среды, т.е. позволяет создавать лазеры с распределенными брэгговскими отражателями и с распределенной обратной связью.

Следует отметить еще одну интересную особенность ФТР стекла. В состав ФТР стекла входят ионы серебра. При облучении УФ излучением и последующей термообработке при невысоких температурах в ФТР стекле формируются молекулярные серебряные кластеры, которые люминесцируют в видимом диапазоне спектра под действием УФ излучения. Такой подход позволяет создавать люминесцентные центры в объеме ФТР стекла и соответственно получать люминесцентное изображение, т.е. можно создавать люминесцентные рисунки сложной архитектуры. На рис. 4 показаны варианты такой технологии. Ионы серебра также можно вводить в поверхностные слои ФТР стекла ионным обменом. Этот подход позволяет формировать люминесцентные волноводы [24].

Важным фактором является то, что ФТР стекло позволяет реализовывать комбинацию фото-термоиндуцированной кристаллизации, ионного обмена и травления. То есть возможно создание оптических, люминесцентных и плазмонных волноводов как на поверхности ФТР стекла, так и внутри полых структур.

Отмеченные особенности ФТР стекол позволяют разрабатывать и демонстрировать широкий спектр голографических оптических элементов и устройств для фотоники, лазерной техники и метрологии.

Можно отметить вклад компаний OptiGrate и Ondax (в 2018 г. вошедших в состав соответственно IPG и Coherent, США) в создание коммерческого производства дифракционных оптических элементов для лазерной техники на основе ФТР стекла. Прежде всего это про- изводство и выпуск на рынок широкой линейки сверхузкополосных спектральных и пространственных фильтров, WDM устройств, комбайнеров мощных лазерных пучков, чирпированных решеток для компрессии световых импульсов, фильтров, повышающих спектральную яркость лазерных диодов, фильтров для стабилизации длины волны лазерных диодов и т.д. [25].

Университет ИТМО также внес существенный вклад в разработку самого ФТР стекла и элементной базы нового поколения для задач фотоники. К таким разработкам прежде всего можно отнести изучение процессов фото-термоиндуцированной кристаллизации и механизмов изменения показателя преломления классического „фторидного“ ФТР стекла $[9,18,26]$. Эти исследования легли в основу создания новых ФТР стекол. К ним можно отнести разработку „бромидных“ (с нанокристаллами $\mathrm{NaBr}-\mathrm{AgBr}$ ) и „хлоридных“ (с нанокристаллами $\mathrm{NaCl}-\mathrm{AgCl})$ ФТР стекол [27,28], у которых изменение показателя преломления положительное по сравнению со „фторидными“ (с нанокристаллами NaF) ФТР стеклами, имеющими отрицательное изменение показателя преломления. Эти стекла открывают возможность записи волноводных структур при использовании сфокусированного лазерного излучения как на поверхности ФТР стекла, так и в его объеме.

Университет ИТМО воспроизвел практически всю линейку голографической продукции, производимой OptiGrate и Ondax $[6,15]$. Следует также отметить следующие дополнительные разработки университета:

сверхузкополосные спектральные фильтры с шириной полосы 5 pm для повышения спектральной яркости и температурной стабилизации длины волны излучения лазерных диодов (совместно с ФТИ им. А.Ф. Иоффе PAH) [29];

голографические призмы на основе мультиплексных брэгговских решеток (более 20 решеток, записанных в единичном объеме) для калибровки высокоточных угловых приборов (совместно с концерном „ЦНИИ ,Электроприбор“) [30];

- изображающие голографические метки для коллиматорных голографических прицелов [31];

- базовые элементы для очков дополненной реальности на основе подхода монолитной интеграции волноводной пластины из ФТР стекла с записанными в ней мультиплексными голограммами для ввода и вывода информации (совместно с МГТУ им. Н.Э. Баумана) [32];

- на лазерных ФТР стеклах, активированных неодимом, эрбием и иттербием, получена генерация, что открывает возможности реализации в стекле идеологии монолитной интеграции брэгговских решеток и лазерной среды, по аналогии с полупроводниковыми лазерами с распределенной обратной связью $[19,20]$.

Таким образом, можно заключить, что ФТР стекла имеют большой потенциал как голографическая и лазерная среда, и, несомненно, такие материалы будут востребованы при создании элементов и устройств фотоники нового поколения. 


\section{Ниобат лития $\mathrm{LiNbO}_{3}$}

Ниобат лития является одним из самых широко применяемых материалов в современной фотонике. Кристаллы ниобата лития $\mathrm{LiNbO}_{3}$ выращиваются из расплава методом Чохральского. Кристаллы являются сегнетоэлектриком с температурой фазового перехода (температура Кюри) $1210^{\circ} \mathrm{C}$. Используемые для голографической записи образцы предварительно монодоменизируются путем нагревания до температуры выше, чем температура фазового перехода, и затем медленно охлаждаются во внешнем электрическом поле. Ниобат лития имеет гексагональную структуру и относится к точечной группе $3 \mathrm{~m}$. Кристаллы, допированные железом, обладают достаточной чувствительностью к голографической записи в сине-зеленой области спектра (примерно $1 \mathrm{~J} / \mathrm{cm}^{2}$ ). Были разработаны достаточно эффективные методы фиксирования записанных голограмм и их последующего неразрушающего считывания [33-36]. В кристалле наблюдается линейный электрооптический эффект с высокими электрооптическими коэффициентами.

Кристалл - одноосный, с оптической осью $C$, которая направлена вдоль оси симметрии третьего порядка. Оптическая ось совпадает по направлению с осью спонтанной поляризации (полярной осью). Диэлектрический тензор и тензор электрооптических коэффициентов имеет вид $[37,38]$

$$
\widehat{\varepsilon}=\left|\begin{array}{ccc}
\varepsilon_{a} & 0 & 0 \\
0 & \varepsilon_{a} & 0 \\
0 & 0 & \varepsilon_{c}
\end{array}\right|, \quad \widehat{r}=\left|\begin{array}{ccc}
0 & -r_{22} & r_{13} \\
0 & r_{22} & r_{13} \\
0 & 0 & r_{33} \\
0 & r_{51} & 0 \\
r_{51} & 0 & 0 \\
-r_{22} & 0 & 0
\end{array}\right| .
$$

Здесь для электрического поля низкой частоты: $\varepsilon_{a}=84$, $\varepsilon_{c}=30, r_{33}=32.2 \mathrm{pm} / \mathrm{V}, r_{13}=10 \mathrm{pm} / \mathrm{V}, r_{51}=32 \mathrm{pm} / \mathrm{V}$, $r_{22}=6.7 \mathrm{pm} / \mathrm{V}$, значения электрооптических коэффициентов приведены для длины волны света $633 \mathrm{~nm}$. Подробный обзор голографических свойств ниобата лития можно найти в работе [39].

Одной из главных особенностей этого материала является наличие электрооптического эффекта. Изменение показателя преломления, вызванное эффектом Поккельса, описывается линейным выражением [40]:

$$
\Delta n_{z, \mathrm{LiNbO}_{3}} \approx n_{e}-\frac{1}{2} n_{e}^{3} r_{33} E_{z} .
$$

Здесь $n_{e}-$ показатель преломления для необыкновенной волны, $E_{z}$ - величина электрического поля, приложенного вдоль оси $z$. Прикладываемое поле никак не влияет на поглощение материала в оптическом диапазоне.

Проводимость материала зависит от вида допанта и от степени допирования. Фотопроводимость номинальночистых и допированных кристаллов $\mathrm{LiNbO}_{3}$ исследовались в работах [41-44]. Для образцов, сильно допированных железом $(0.2 \mathrm{wt} \% \mathrm{Fe})$, проводимость составляет
$1.5 \cdot 10^{-14} \ldots 1.4 \cdot 10^{-14} I\left(\mathrm{~W} / \mathrm{cm}^{2}\right)$, где $I-$ интенсивность света. Как показано в $[45,46]$, основной механизм темновой проводимости для ниобата лития это ионная проводимость с энергией активации $1.1 \mathrm{eV}$ и характерным временем диэлектрической релаксации $\tau_{\mathrm{M}} \sim 10^{6} \mathrm{~s}$. Фотопроводимость связана с возбуждением электронов с донорного уровня $\mathrm{Fe}^{2+}$. В допированных кристаллах наблюдается сильный фотогальванический эффект $[47,48]$. Значение возникающего под действием света фотогальванического поля в сильно допированных кристаллах может достигать $50 \ldots 70 \mathrm{kV} / \mathrm{cm}$.

Ниобат лития оказался первым материалом, в котором был обнаружен фоторефрактивный эффект [49]. Позднее было предложено использовать этот эффект для записи фазовых голографических решеток в [50,51]. В стандартной геометрии используется схема записи пропускающих голограмм. Ось $C$ в этой геометрии лежит в плоскости падения записывающих лучей, волновой вектор решетки параллелен оптической оси, записывающие лучи имеют одинаковую произвольно ориентированную линейную поляризацию. Падающий (т.е. считывающий) и восстановленный (продифрагировавший) лучи имеют необыкновенную поляризацию.

Существуют работы, описывающие использование голографических решеток в ниобате лития в отражательной геометрии в оптимальной ориентации кристалла [52-54]. Применительно к управляемым оптическим DWDM фильтрам отражательные брэгговские решетки исследовались в [55-57]; применительно к адаптивным голографическим интерферометрам в [58].

\section{Примеры использования отражательных решеток Брэгга на основе ФТР стекла и ниобата лития для квантовых коммуникаций}

В последние годы особый интерес к отражательным решеткам Брэгга возник со стороны бурно развивающихся систем оптических, в том числе когерентных и квантовых коммуникаций. Для таких систем необходимы высокостабильные узкополосные полупроводниковые лазеры. Уже сейчас ширина полосы их излучения должна быть менее $1 \mathrm{MHz}$, а в перспективе - порядка нескольких килогерц. Отражательная решетка Брэгга, установленная в резонатор лазера, потенциально позволяет решать поставленную задачу. Одно из главных требований, предъявляемое в данном случае к материалу, - высокая радиационная стойкость, так как удельная мощность излучения внутри резонатора может составлять десятки ватт на квадратный миллиметр. В этом случае оптические фильтры на основе фото-терморефрактивных стекол являются удачным решением.

Другой важной задачей в системах квантовых коммуникаций, использующих боковые частоты, является задача подавления центральной, несущей частоты. В этом случае требуется узкополосный оптический фильтр с 

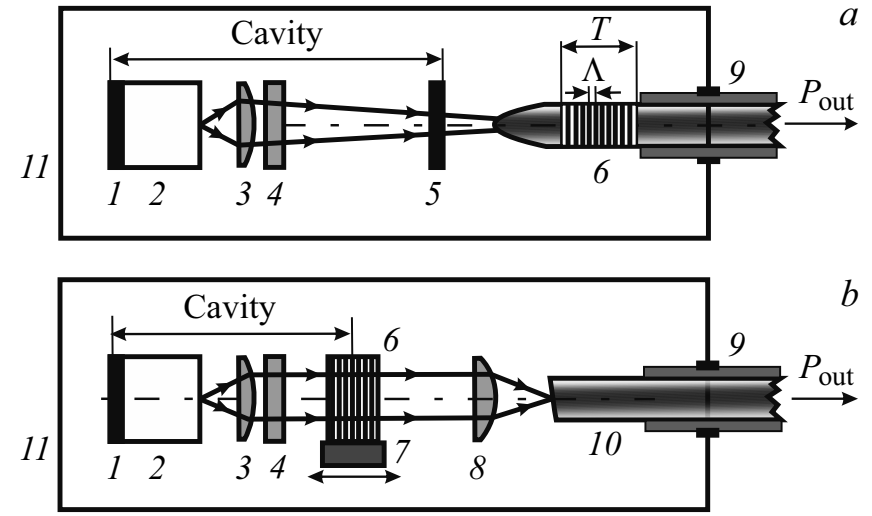

Рис. 5. Полупроводниковый лазер с решеткой Брэгга на основе ФТР стекла в качестве спектрально-селективного элемента. Решетка Брэгга расположена в оптическом волокне $(a)$; решетка Брэгга является выходным зеркалом лазера $(b) .1-$ глухое зеркало, 2 - активный элемент, 3, 4 - коллимирующие цилиндрические линзы, 5 - выходное зеркало, 6 - выходное зеркало в виде решетки Брэгга, 7 - электрически управляемая пьезо-подставка, 8 - фокусирующая линза, $9-$ фиксирующая муфта, 10 - оптическое волокно, 11 - корпус.

небольшой по величине, но быстрой и точной перестройкой по длине волны. Для этой задачи особо подходят электрически-управляемые оптические фильтры, изготовленные из ниобата лития.

Отражательные решетки Брэгга обладают высокой спектральной селективностью:

$$
\frac{\Delta \lambda}{\lambda} \approx \frac{\Lambda}{T}
$$

Здесь $\Delta \lambda-$ ширина селектируемой полосы. При практически достижимых толщинах решетки в отражательной геометрии $T \sim 5-30 \mathrm{~mm}$ и характерном для телекоммуникационного диапазона длин волн периоде решетки $\Lambda \sim 300-400 \mathrm{~nm}$ ее селективность может достигать долей нанометров, что позволяет использовать такие решетки в качестве высокодобротных оптических фильтров [59-62].

Пример использования отражательной решетки Брэгга в качестве одного из элементов полупроводникового лазера показан на рис. 5, $a, b$. На рис. 5, $a$ показан хорошо известный случай, когда отражательная решетка Брэгга (6) создана в отрезке оптического волокна, находящегося внутри корпуса (11), но снаружи оптического резонатора, сформированного зеркалами (1) и (5). Наличие решетки Брэгга в этом случае позволяет кардинальным образом улучшить спектральные характеристики излучения. Хорошо известны и проблемы, связанные с заметной нестабильностью параметров решетки Брэгга, сформированной в оптическом волокне, вызванной температурными флуктуациями. Решением проблемы температурной стабилизации является решетка Брэгга, созданная в ФТР стекле и расположенная на пьезоподставке (рис. 5,b). Пьезо-подставка (7) управляется электрическим сигналом, что позволяет перемещать решетку Брэгга вдоль оси резонатора и тем самым производить необходимую подстройку резонатора в реальном масштабе времени. Схема лазера, представленная на рис. $5, b$, позволяет обеспечивать высокостабильную полосу генерации одномодового излучения с шириной меньше 1 МГц, что является принципиальным требованием для систем квантовой рассылки ключа на боковых частотах.

Другой пример использования отражательной решетки Брэгга для систем квантовых коммуникаций узкополосный перестраиваемый оптический фильтр для подавления несущей. В этом случае эффективным решением является отражательная решетка Брэгга, сформированная в поверхностном оптическом волноводе (рис. 6). Использование подложки из ниобата лития $Z$-среза позволяет эффективно управлять показателем преломления, что, в свою очередь, позволяет управлять величиной длины волны Брэгга $\lambda_{\mathrm{B}}$ в отражательной геометрии:

$$
\lambda_{\mathrm{B}}=2\left(n \pm \Delta n_{z, \mathrm{LiNbO}_{3}}\right) E_{z} .
$$

Как видно из приведенного рисунка, ширина полосы такого фильтра составила примерно $0.2 \mathrm{~nm}$, а диапазон перестройки - примерно $1 \mathrm{~nm}$, что вполне удовлетворяет требованиям систем квантовых коммуникаций. К другому достоинству такого фильтра следует отнести возможность его непосредственного „интегрирования“ в линию связи за счет склейки торцов волновода с торцами входного и выходного волокон.

\section{Заключение}

Рассмотренные в настоящей работе фоторефрактивные стекла и кристаллы представляют заметную часть неорганических голографических материалов, используемых в современных применениях.

Голографическая запись в фоторефрактивных материалах происходит за счет изменения показателя преломления под действием записывающего света. В случае ФТР стекла необходимо дополнительное проявление голограммы в виде термообработки. В материале возникает фазовая голограмма, т.е. периодическая решетка изменения показателя преломления. Амплитуда такой решетки может достигать величин $10^{-2}-10^{-4}$. Вклад решетки поглощения, которая возникает как следствие соотношения Крамерса-Кронига вместе с фазовой решеткой, в случае фоторефрактивных материалов оказывается пренебрежимо малым. Это обеспечивает высокое качество записанных фазовых голограмм и сохранение высокой прозрачности материала во всех фоторефрактивных материалах.

Заметное различие между фоторефрактивными стеклами и кристаллами наблюдается в величине фоточувствительности к записывающему свету, которая на 2-3 порядка лучше у фоторефрактивных кристаллов. 

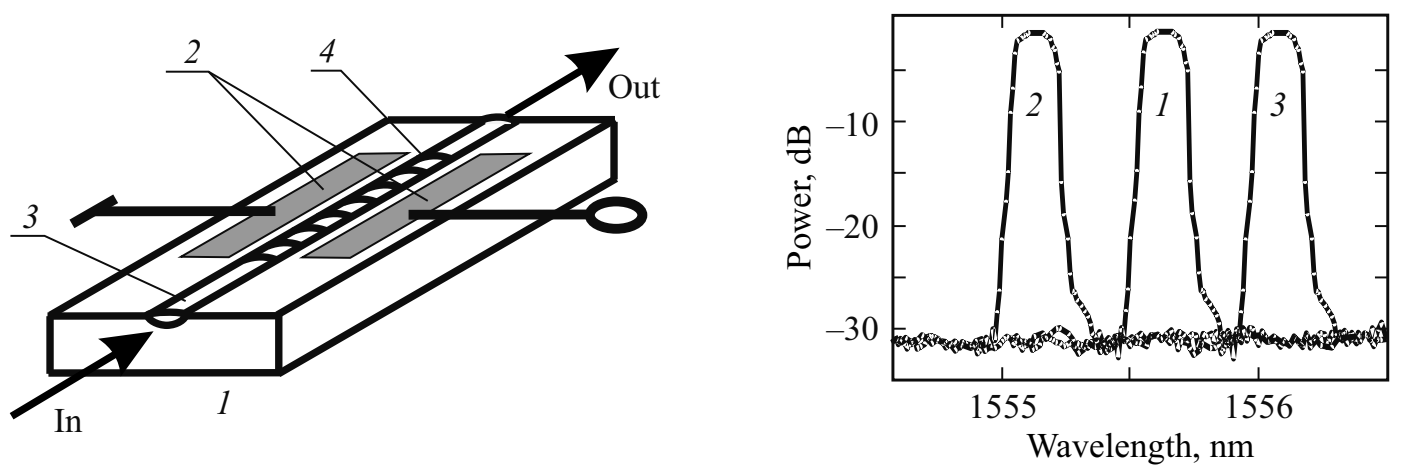

Рис. 6. Слева - электрически-перестраиваемый фильтр в интегральном исполнении. Справа - демонстрация перестройки передаточной функции фильтра по длине волны в зависимости от приложенного электрического поля. $E_{\mathrm{ext}}=0(1),-15(2)$, $+15 \mathrm{~V} / \mu \mathrm{m}(3)$. Полный диапазон переключения составил примерно $1 \mathrm{~nm}$.

Однако следует учитывать, что это приводит к гораздо более низкой стойкости и к считывающему свету.

Фоторефрактивные стекла отличаются высокой стабильностью своих параметров по отношению к изменениям температуры, наличию внешних электрических полей, механическим воздействиям, что является следствием их принадлежности к классу аморфных, оптически изотропных материалов. Фоторефрактивные кристаллы в силу принадлежности к анизотропным материалам являются двулучепреломляющими и обладают целым набором эффектов: электрооптическим, фотогальваническим, пьезоэлектрическим, акустооптическим, эластооптическим и т.д. С одной стороны, это влечет за собой определенные проблемы при практическом использовании устройств на их основе. Так, например, наличие двулучепреломления у ниобата лития приводит к заметной зависимости дифракции от ориентации поляризации падающего света. С другой стороны наличие электрооптических свойств у фоторефрактивных кристаллов позволяет осуществлять эффективное электрическое управление условиями дифракции, что востребовано в различных практических применениях.

\section{Конфликт интересов}

Авторы заявляют, что у них нет конфликта интересов.

\section{Список литературы}

[1] Klein W.R. // Proc. IEEE. 1966. V. 54. N 5. P. 803.

[2] Collier R.J., Burckhardt C.B., Lin L.H. Optical Holography, NY:: Academic Press, 1971. 605 p.

[3] Gleı̆m A.V., Chistyakov V.V., Bannik O.I. // J. Optical Technology. 2017. V. 84. N 6. P. 362. doi 10.1364/JOT.84.000362

[4] Погода А.П., Хахалин И.С., Попов Е.В., Истомина Н.Л., Борейшо А.С., Петров В.М. // Квант. электрон. 2020. Т. 50. № 7. C. 658; Pogoda A.P., Sergeev A.A., Khakhalin I.S., Popov E.V., Istomina N.L., Boreisho A.S., Petrov V.M. // Quantum Electronics. 2020. V. 50. N 7. P. 658.

[5] Pierson J.E., Stokey S.D. Patent 4017318 US, 1977.

[6] Pierson J.E., Stokey S.D. Patent 4057408 US, 1977.
[7] Stokey S.D., Beal G.H., Pierson J.E. // J. Appl. Phys. 1978. V. 49. N 10. P. 5114.

[8] Dotsenko A.V., Efremov A.M., Zakharov V.K., Panysheva E.I., Tunimanova I.V. // Phys. and Chem. of Glass. 1985. V. 11. N 5. P. 592.

[9] Panysheva E.I., Tunimanova I.V., Tsehomskii V.A. // Phys. and Chem. of Glass. 1990. V. 16. N 2. P. 239.

[10] Nikonorov $N$., Ivanov $S$., Dubrovin $V$., Ignatiev A. // Holographic materials and optical systems / Ed. by Nayadenova I., Nazarova D., Babeva T. InTech. 2017. P. 435.

[11] Nikonorov N.V., Panysheva E.I., Savin V.V., Tunimanova I.V.// Proc. All-Union Conference „Optical Image and Recording Media“, Leningrad: GOI, 1990. V. 2. P. 48.

[12] Glebov L.B., Nikonorov N.V., Panysheva E.I. Tunimanova I.V., Savvin V.V., Tsekhomskii V.A. // Proc. VII All-Union Conference on Radiation Physics and Chemistry of Inorganic Materials, Riga: IF AN Latv. SSR, 1989. Pt 2. P. 527.

[13] Glebov L.B., Nikonorov N.V., Panysheva E.I. Tunimanova I.V., Savvin V.V., Tsekhomskii V.A. // Dokl. Akad. Nauk USSR. 1990. V. 314. N 4. P. 849.

[14] Kuchinskii S.A., Nikonorov N.V., Panysheva E.I. Tunimanova I.V., Savvin V.V. // Opt. Spectrosc. 1991. V. 70. N 6. P. 1296.

[15] Glebov L.B., Glebova L.N., Richardson K.A., Smirnov V.I. // Proc. XV Congress on Glass, San Francisco: Am. Ceram. Soc. 1998.

[16] Efimov O.M., Glebov L.B., Glebova L.N., Richardson K.A., Smirnov V.I. // Appl. Opt. 1999. V. 38. N 2. P. 619.

[17] Glebov L.B. // Proc. SPIE. 2007. V. 6545. P. 654507.

[18] Nikonorov N., Aseev V., Dubrovin V., Ignatiev A., Ivanov S., Sgibnev Y., Sidorov A. // Optics, Photonics and Laser Technology / Ed by Ribeiro P., Raposo M. Springer Series in Optical Sciences, Springer Verlag, 2018. V. 218. P. 83.

[19] Sgibnev Y., Nikonorov N., Vasilev V.N., Ignatiev A. // J. Lightwave Technology. 2015. V. 33. N 17. P. 3730.

[20] Sgibnev Y., Nikonorov $N$., Ignatiev A., Vasilev V., Sorokina M. // Opt. Express. 2016. V. 24. N 5. P. 4563.

[21] Aseev V., Nikonorov N. // J. Optical Technologies. 2008. V. 75. P. 676.

[22] Nikonorov N.V., Ivanov D.A., Kozlova I.S., Pichugin I.S. // Proc. SPIE. 2017. V. 10233. P. 102330.

[23] Nasser K., Aseev V., Ivanov S., Ignatiev A., Nikonorov N. // J. Luminescence. 2019. V. 213. P. 255. 
[24] Sgibnev Y., Asamoah B., Nikonorov N., Honkanen S. // J. Luminescence. 2020. V. 226. P. 117411.

[25] Электронный ресурс. Режим доступа https://optigrate.com

[26] Ivanov S., Dubrovin V., Nikonorov N., Stolyarchuk M., Ignatiev A. // J. Non-Crystalline Solids. 2019. V. 521. P. 119496.

[27] Dubrovin V., Nikonorov N., Ignatiev A. // Optical Materials Express. 2017. V. 7. N 7. P. 2280.

[28] Klyukin D., Krykova V., Ivanov S., Obraztsov P., Silvenionen M., Nikonorov N. // Optical Materials Express. 2017. V. 7. N 11. P. 4131.

[29] Ivanov S., Nikonorov N., Ignat'ev V., Zolotarev V.V., Lublanskiy Ya.V., Pikhtin N.A., Tarasov I.S. // Semiconductors. 2016. V. 50. N 6. P. 819.

[30] Angervaks A.E., Gorokhovskii K.S., Granovskii V.A., Doan V.B., Ivanov S.A., Okun' R.A., Nikonorov N.V., Ryskin A.I. // Opt. Spectrosc. 2017. V. 123. N 6. P. 970.

[31] Ivanov V.A., Angervaks A.E., Shcheulin A.S., Ignatiev A.I., Nikonorov N.V. // Opt. Spectrosc. 2014. V. 117. N 6. P. 971.

[32] Odinokov S., Shishova M., Markin V., Zherdev A., Lushnikov D., Solomatenko A., Kuzmin D., Nikonorov N., Ivanov S. // Optics Express. 2020. V. 28. N 12. P. 17581.

[33] Chen F.C., Macchia T., Fraser D.F. // Appl. Phys. Lett. 1968. V. 13. N 7. P. 225.

[34] Куликов В.В., Степанов С.И. // ФТТ. 1979. Т. 21. № 11. C. 3204.

[35] Бобринёв В.И., Васильева З.Г., Гуланян Э.Х., Микаэлян А.Л. // Письма в ЖТФ. 1973. Т. 18. № 4. С. 267.

[36] Куликов В.В., Петров М.П., Степанов С.И. // Автометрия. 1980. № 1. С. 39.

[37] Ярив А., Юх П. Оптические волны в кристаллах. М.: Мир, 1987. $616 \mathrm{c}$

[38] Кузьминов Ю.С. Ниобат и танталат лития. Материалы для нелинейной оптики. М.: Наука, 1975. 224 с.

[39] Петров В.М., Шамрай А.В. Интерференция и дифракция для информационной фотоники. СПб.: Лань, 2019. 460 с.

[40] Петров В.М., Шамрай А.В. // УФН. 2021. doi 10.3367/UFNr.2020.11.038871

[41] Kratzig E., Kurz H. // Optics Acta. 1977. V. 24. P. 475.

[42] Ohmori Y., Yasojima Y., Inuish Y. // Technical Reports of Osaka University. 1974. V. 24. N 1166. P. 105.

[43] Ohmori Y., Yasojima Y., Inuish Y. // Jap. J. Appl. Phys. 1975. V. 14. N 9. P. 1291.

[44] Пашков В.А., Соловьёва Н.М., Уюкин В.М. // ФТТ. 1979. T. 21. № 6. C. 1879.

[45] Amodei J.J., Staebler D.L. // Appl. Phys. Lett. 1971. V. 18. N 12. C. 540.

[46] Staebler D.L., Burke W.J., Phillips W., Amodei J.J. // Appl. Phys. Lett. 1975. V. 26. N 4. P. 182.

[47] Стурман Б.И., Фридкин В.М. Фотовольтаический эффект в средах без центра симметрии и родственные явления. М.: Наука, 1992. 208 с.

[48] Glass A.M., Linde D., Auston D.H. // J. Electronics Mater. 1975. V. 4. N 5. P. 915.

[49] Ashkin A. // Appl. Phys. Lett. 1966. V. 9. P. 72.

[50] Petrov M.P., Stepanov S.I., Kamshilin A.A. // Ferroelectrics. 1978. V. 21. P. 631.

[51] Huignard J.P., Micheron F. // Appl. Phys. Lett. 1976. V. 29. P. 591.

[52] Петров М.П., Шамрай А.В., Петров В.М. // ФТТ. 1998. T. 40. № 6. C. 1038.
[53] Petrov M.P., Shamray A.V., Petrov V.M., Sanchez-Mondragon J. // Opt. Commun. 1998. V. 153. P. 305.

[54] Шамрай А.В., Петров В.М., Петров М.П. // ЖТФ. 1999. T. 69. № 9. С. 110.

[55] Breer S., Buse K. // Appl. Phys. B. 1998. V. 66. P. 339.

[56] Petrov V.M., Denz C., Shamray A.V., Petrov M.P., Tschudi T. // Opt. Mater. 2001. V. 18. N 1. P. 191.

[57] Petrov V.M., Denz C., Shamray A.V., Petrov M.P., Tschudi T. // Appl. Phys. B. 2000. V. 71. P. 43.

[58] Петров В.М. Адаптивные голографические интерферометры для наномеханики. СПб.: Лань, 2018. 192 с.

[59] Petrov V.M., Karaboue C., Petter J., Tschudi T., Bryksin V.V., Petrov M.P. // Appl. Phys. B. 2003. V. 76. N 1. P. 41.

[60] Petrov V.M., Lichtenberg S., Petter J., Tschudi T., Chamrai A.V., Bryksin V.V., Petrov M.P. // J. Opt. A: Pure and Appl. Opt. 2003. V. 5. N 6. P. 471.

[61] Arora P., Petrov V.M., Petter J., Tschudi T. // Opt. Commun. 2008. V. 281. N 6. P. 1455.

[62] Arora P., Petrov V.M., Petter J., Tschudi T. // Opt. Commun. 2008. V. 281. N 8. P. 2067. 